\title{
Health Service Utilization and Out-Of-Pocket Health Expenditure Among Insured and Uninsured: A Comparative Study in Baglung District, Nepal
}

Laxman Datt Bhatt ( $\square$ laxmanbhattbph@gmail.com )

Pokhara University https://orcid.org/0000-0001-5488-6300

Shankar Singh Dhami

Pokhara University

Dipendra Kumar Yadav

Pokhara University

\section{Research article}

Keywords: Financial burden, Health insurance, Health service utilization, National health insurance, Outof-pocket expenses, Social health insurance.

Posted Date: December 30th, 2019

DOI: https://doi.org/10.21203/rs.2.14596/v2

License: (c) (i) This work is licensed under a Creative Commons Attribution 4.0 International License. Read Full License 


\section{Abstract}

Background Nepal's Interim Constitution of 2007 addresses health as a fundamental right, stating that every citizen has the right to basic health services free of cost. Government of Nepal formed a Social Health Security Development Committee as a legal framework to start implementing a social health security scheme after the National Health Insurance Policy came out in 2013. The program has aimed to increase the access of health services to the poor and the marginalized, and people in hard to reach areas of the country, though challenges remain with financing. Several aspects should be considered in design, learning from earlier community-based health insurance schemes that suffered from low enrollment and retention of members as well as from a pro-rich bias. Method A community based cross-sectional comparative study was conducted in Baglung district of Nepal to find out and compare the health service utilization and direct out-of-pocket health care expenditure among the 225 insured and 225 uninsured households under the national health insurance program of Nepal. Insured households were randomly chosen from study area and uninsured households were selected by using neighborhood method. Result The study focused that insurance status was strongly associated with heath service utilization with odds ratio $1.774(95 \% \mathrm{Cl}=1.127-2.791, \mathrm{P}=0.013)$. The study also depicts that insurance status was major determinants of out of pocket health expenditure. The median out-of-pocket health expenditure among insured households Nepalese Rupees 200 while among uninsured was 1225, which was statistically significant ( $p=<0.001 \mathrm{MW}-\mathrm{U}$ test). Among uninsured group, non-dalit were 2.846 times more likely to utilize health services compared to the dalit $(p=0.003)$ but it was not significant $(p=0.47)$ among insured group.Conclusion Nepal's Health Insurance Board is responsible for purchasing the quality health care service and make available at possible nearest point of its member. Our study reveals that Occupation, perceived health status, wealth status played significant role with health service utilization among uninsured group while it was not significant among insured group. Among both insured and uninsured group none of the study variables were found significant with out-of-pocket health expenditure.

\section{Background}

Out of pocket health expenditure was found highest in South East Asia Region than other region[1-3]. High in out of pocket health expenditure in developing country creates financial barrier to access and utilization of health services[2, 3]. World Health Assembly passed a resolution on social health insurance for considering universal health coverage in 2005. It advocates universal health coverage by sustainable access to the quality health care services[4]. World health report 2010 also advocated for copayment in the health or health insurance. This report also identified health insurance is among one strong mechanism of universal health coverage[ 5]. To improving access towards quality health care services, several countries have started different type of health insurance program; however the name provision and packages are not similar[ $1,3,6]$.

In context of Nepal poverty and high OOP health expenditure remains challenging for equitable access to quality health care services[7, 8]. To overcoming above challenges Government of Nepal introduces national health insurance policy in 2013 with objective of ensured universal health coverage[ 9,10$]$. 
Based on health insurance policy, Government of Nepal started national health insurance program from 2015[10].

\section{National Health Insurance Program}

National Health Insurance Program (NHIP) is a social protection program of the Government of Nepal that aims to enable its citizens to access quality health care services minimizing the financial burden on them[8-10]. National Health Insurance Program has been rolled out in various districts since 2016[10]. It is a family-based health insurance scheme that aims to address barriers in health service utilization and ensure equity and access of poor and disadvantaged groups as a means to achieve Universal Health Coverage[9, 10]. For the purpose of National Health Insurance Program (NHIP) family was taken as unit. The NHIP currently operates in twenty two districts of the country and the program will be expanded to addition fifteen districts by October 2017[10].Social Health Security Development Committee (SHSDC) aims to expand NHIP program to all 75 districts by 2020[11].

The vision of the SHSDC is to improve the overall health situation of the people of Nepal and main objectives is to insure the universal health coverage by increasing access to, and utilization of, necessary quality health services[11].

\section{Methods}

A comparative cross-sectional, quantitative study was conducted among 225 insured and 225 uninsured households in Baglung district of Nepal. Primary data were collected from March-April, 2018 12-14.

Sample size was calculated by using the compare two proportion formulas. Taking the proportion of health service utilization among insured households was 9.27 present and among uninsured households was 3.09 present. The proportion of health service utilization was estimated from pilot study, which was conducted in Pokhara-Lekhnath metropolitan, Kaski, Nepal. From calculation the sample size arrived at 225. For comparative study the 225 sample households from each group were taken (Total 450 households were selected for study). Random sample method was used to select study households. In figure 1 , seven wards were selected from fourteen wards of municipality randomly and based on the proportion of insured households in each selected ward, sample was taken proportionally by lottery method. Uninsured households were selected by using neighborhood control method. For each insured household one nearest uninsured household was chosen for comparison group

Data were entered in Epi-Data software and exported in Statistical Package for Social Sciences (SPSS) version 16.0 for further analysis. The comparison was made between insured and uninsured households' characteristics by using cross tabulation. Bi-variate logistic regression was performed to identify the association of insurance status and other variables with health service utilization. And Mann-Whitney $U$ test was performed to compare the out of pocket expenditure among insured and uninsured group. Research study period was October to March 2018. 
Data collection was done after pretesting of structured questionnaire by researcher and trained research assistant. In case of participants refused to participate, the household was replaced by similar nearest household.

\section{Results}

A total of 225 insured and 225 uninsured households having 1242 and 1218 members were included in the study. Uni-variate analysis was described on the basis of insurance enrollment status. According to objective bi-variate analysis was done based on service utilization and OOP expenditure among insurance status.

\section{Table 1. Descriptive analysis of households characteristics}

\section{Basic Characteristics of Households}

Majority of households were headed by male, which was almost similar among both insured $(74.2 \%)$ and uninsured $(68.4 \%)$ households. There was a significant difference in religion of insured and uninsured households; $p=0.009$. Similarly, ethnicity also found significantly different among the both insured and uninsured group; $p<0.001$. Occupation $p=0.003$, wealth status $p=0.025$ and time to reach health facility $p=0.017$ were found significantly different among the insured and uninsured households. Most of independent variables like age, education, number of family member, health system preferred, chronic disease/disability and perceived health status were not found significantly different among both insured and uninsured group.

Table 2. Associated factors with health service utilization 


\begin{tabular}{|c|c|c|c|}
\hline Characteristics & Insured n (\%) & Uninsured n (\%) & $p$ Value \\
\hline \multicolumn{4}{|l|}{ Age in years } \\
\hline$\leq 30$ & $6(2.7)$ & $13(5.8)$ & 0.511 \\
\hline $31-45$ & $61(27.1)$ & $58(25.8)$ & \\
\hline $46-60$ & $92(40.9)$ & $84(37.3)$ & \\
\hline $61-75$ & $56(24.9)$ & $61(27.1)$ & \\
\hline$\geq 76$ & $10(4.4)$ & $9(4)$ & \\
\hline \multicolumn{4}{|l|}{ Sex } \\
\hline Male & $167(74.2)$ & $154(68.4)$ & 0.175 \\
\hline Female & $58(25.8)$ & $71(31.6)$ & \\
\hline \multicolumn{4}{|l|}{ Religion } \\
\hline Hindu & $175(77.8)$ & $198(88)$ & 0.009 \\
\hline Buddhist & $36(16)$ & $18(8)$ & \\
\hline Christian & $8(3.6)$ & $8(3.6)$ & \\
\hline Islam & $6(2.7)$ & $1(0.4)$ & \\
\hline \multicolumn{4}{|l|}{ Ethnicity } \\
\hline Dalit & $27(12)$ & $44(19.6)$ & $<0.001$ \\
\hline Janajati & 66 (29.3) & $40(17.8)$ & \\
\hline Muslim & $8(3.6))$ & $0(0)$ & \\
\hline Brahamn/Chhetri & $124(55.1)$ & $141(62.7)$ & \\
\hline \multicolumn{4}{|l|}{ Education } \\
\hline Illiterate & $37(16.4)$ & $38(16.9)$ & 0.320 \\
\hline Literate & $38(16.9)$ & 49 (21.8) & \\
\hline Basic & $54(24)$ & $63(28)$ & \\
\hline Secondary & $72(32)$ & $57(25.3)$ & \\
\hline Higher & $24(10.7)$ & $18(8)$ & \\
\hline \multicolumn{4}{|c|}{ Number of family member } \\
\hline$\leq 5$ & $129(57.3)$ & $136(60.4)$ & 0.502 \\
\hline$\geq 6$ & $96(42.7)$ & 89 (39.6) & \\
\hline \multicolumn{4}{|l|}{ Occupation } \\
\hline Agriculture/Labor & $74(32.9)$ & $111(49.3)$ & 0.003 \\
\hline Business & $49(21.8)$ & $33(14.7)$ & \\
\hline Foreign employment & $46(20.4)$ & 30 (13.3) & \\
\hline Service & $56(24.9)$ & $51(22.7)$ & \\
\hline \multicolumn{4}{|l|}{ Wealth Status } \\
\hline Lowest quintile & $12(5.3)$ & $17(7.6)$ & 0.025 \\
\hline First quintile & $18(8)$ & $28(12.4)$ & \\
\hline Second quintile & $57(25.3)$ & $68(30.2)$ & \\
\hline Third quintile & $59(26.2)$ & $63(28)$ & \\
\hline Highest quintile & $79(35.1)$ & 49 (21.8) & \\
\hline \multicolumn{4}{|c|}{ Chronic disease/disability } \\
\hline Yes & $108(48)$ & $96(42.7)$ & 0.256 \\
\hline No & $117(52)$ & $129(57.3)$ & \\
\hline \multicolumn{4}{|c|}{ Perceived health status } \\
\hline Good & 38 (16.9) & $41(18.2)$ & 0.597 \\
\hline Average & $183(81.3)$ & $177(78.7)$ & \\
\hline Bad & $4(1.8)$ & $7(3.1)$ & \\
\hline \multicolumn{4}{|c|}{ Health system preferred } \\
\hline Allopathic & $206(91.6)$ & $199(88.4)$ & 0.422 \\
\hline Traditional healer & $15(6.7)$ & $18(8)$ & \\
\hline Ayurveda & $4(1.8)$ & $8(3.6)$ & \\
\hline \multicolumn{4}{|l|}{ Time to reach HF } \\
\hline$<30$ & $106(47.1)$ & $124(55.1)$ & 0.017 \\
\hline
\end{tabular}




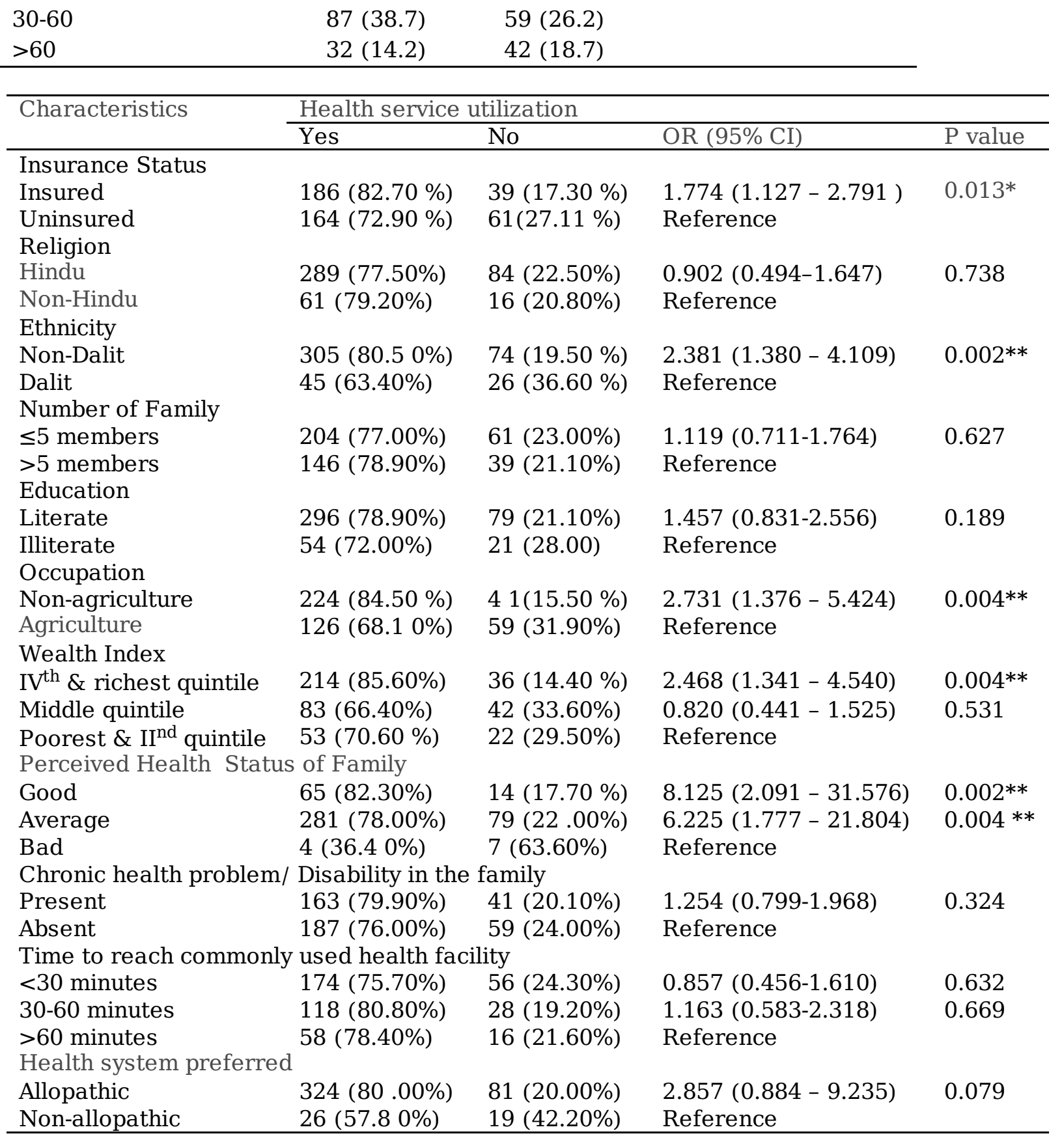

Odd Ratio(OR) and $p$ value based on binary logistic regression, $* p$ value significant at $<0.05$, ** $p$ value significant at $<0.01$.

\section{Health Service Utilization}

The overall health service utilization was found $77.8 \%$. When health service utilization was compared with the insurance status, it was found $82.7 \%$ and $72.9 \%$ among insured and uninsured households respectively. Insured households were $1.774(95 \% \mathrm{Cl}=1.127-2.791)$ times more likely to utilize health services in compared to uninsured households; $p=0.013$. Similarly, among overall households beside insurance status ethnicity, occupation, wealth index and perceived health status of the family were found major predictor of health service utilization. 
Table 3. Associated factors with out-of-pocket health expenditure

\begin{tabular}{|c|c|c|c|}
\hline Variables and it's category & Median OOP (IQR) in NRS & MW-U value & $\mathrm{p}$ value \\
\hline \multicolumn{4}{|l|}{ Insurance status } \\
\hline Insured & $200(1550)$ & \multirow[t]{3}{*}{17988.50} & \multirow[t]{3}{*}{$<0.001 * * *$} \\
\hline Uninsured & $1225(5175)$ & & \\
\hline \multicolumn{2}{|l|}{ Religion } & & \\
\hline Hindu & 700 (3620) & \multirow[t]{3}{*}{13362.50} & \multirow[t]{3}{*}{0.328} \\
\hline Non-Hindu & $500(2250)$ & & \\
\hline \multicolumn{2}{|l|}{ Ethnicity } & & \\
\hline Dalit & $1275(5300)$ & \multirow[t]{3}{*}{11899.50} & \multirow[t]{3}{*}{0.115} \\
\hline Non-Dalit & $600(2800)$ & & \\
\hline \multicolumn{2}{|l|}{ Educational status } & & \\
\hline Illiterate & $700(5000)$ & \multirow[t]{3}{*}{13932} & \multirow[t]{3}{*}{0.897} \\
\hline Literate & $610(2500)$ & & \\
\hline \multicolumn{2}{|l|}{ Occupation } & & \\
\hline Agriculture & $805(4000)$ & \multirow[t]{2}{*}{21294} & \multirow[t]{2}{*}{$0.016^{*}$} \\
\hline Others & $400(2500)$ & & \\
\hline \multicolumn{4}{|l|}{ Wealth status } \\
\hline Up to middle quintile & $720(3791)$ & \multirow[t]{3}{*}{24013} & \multirow[t]{2}{*}{0.463} \\
\hline Fourth \& richest quintile & $500(2575)$ & & \\
\hline \multicolumn{3}{|c|}{ Time to reach health Facility } & \\
\hline$\leq 60$ minutes & $8617(3000)$ & 13283 & 0.531 \\
\hline$>60$ minutes & $700(4272)$ & & \\
\hline
\end{tabular}

$P$ value based on Mann-Whitney $U(M W-U)$ test, ${ }^{*} p$ value significant at $<0.05,{ }^{* *} p$ value significant at $<0.001$.

\section{Out of Pocket Health Expenditure}

For measuring association between OOP health expenditure with insurance status and another covariate we perform Mann Whitney $\mathrm{U}$ test. Considering one-month preceding period for OOP; among insured households the median OOP health expenditure was found NRS $200(I Q R=1550)$ and among uninsured households it was NRS 1225 (IQR = 5175). Among uninsured households median OOP was more than six times higher compared to insured households which was highly significant $(p<0.001)$. Beside insurance status occupation was also found statistically significant with OOP; $p=0.016$.

\section{Discussion}

Primarily this study focuses to look the influence of national health insurance program on the health service utilization and out of pocket expenditure among insured group in compare to uninsured group. In addition, some associated factors were also studied to identify their effects on health service utilization and out of pocket health expenditure.

Health service utilization 
There was positive role of insurance to increase health service utilization rate. In this study insured households found to utilize more health services than those of uninsured, which was statistically significant. Similar finding was reported by the study done in India on comprehensive health insurance program[14]. Similarly findings from our study was consistent with the results of other studies conducted in different types of health insurance program in Ghana, Republic Korea and Chhattisgarh, India[15,16, 17].

We found that insurance status was major predictor of health service utilization. Ethnicity, family occupation, perceived health status of family and wealth status also had significant role in health service utilization among overall households. Similar study conducted in Ghana reported that educational status and monthly income were major determinants of health service utilization among overall study group[15]. The study conducted in Republic Korea reflects educational status and household wealth status had also significant difference in health service utilization[16].

\section{Out-of-pocket health care expenditure}

Health insurance program of Nepal did not completely reduce the OOP health expenditure among insured households. However, it highly reduces the OOP health expenditure among insured household in compared with uninsured households, which was statistically significant. Similar finding was reported by the study conducted in different area of Ghana and Nigeria[17,18 19,20]. There was some discrepancy shown between the out-of-pocket costs of different studies conducted in different countries. It might be because of the different policies and provision of the countries and also due to other associated factors. Another reason for discrepancy might be the study conduct in different timeframe of implementation of health insurance.

The variables ethnicity, religion and occupation found to play role in out-of-pocket health care expenditure however these differences were not statistically significant. Beside insurance status only occupation was found to plays significant role in OOP. Similar finding was reported by the Indian study conducted in Uttar Pradesh, stated that education status, religion, ethnicity and wealth status were determinants of out-ofpocket health expenditure[21].

\section{Conclusions}

This study found that insurance status had positive role to increasing the health service utilization and reducing the OOP health expenditure among the insured household under National health insurance program of Nepal. With insurance status some other independent variables like ethnicity, family occupation, wealth status and perceived family status were had also role in health service utilization and OOP health expenditure. Despite various positive role of National health insurance program of Nepal on increasing health service utilization and reducing out-of-pocket health expenditure, it did not totally control the out-of-pocket health expenditure among the insured. This study also found that large proportion of insured population were not satisfied with health insurance program due to limited service site, limited package and lengthy process for receiving service at hospital. Finally, the results of this study 
suggested for government to full phase nationwide expansion of National health insurance program and advised other researcher to conduct similar research in large scale.

\section{Footnotes}

Definitions and Conceptual framework Health service utilization: Those who reported illness in past 1 month prior to the study. The health care provider visits for outpatient services, inpatient services, laboratory services and delivery services were used to assess health service utilization. Recall period for delivery services was 12 months considering it as rare event. Utilization is defined as seeking healthcare during each episode of illness. Chronic disease: This includes anyone in the household who was continuously taking medicine before three month or need to take medicine more than three month. Direct cost: Direct costs represent the costs associated with the health care service utilization. It includes inpatient, outpatient, laboratory and pharmaceutical services. Disability: It includes blindness/low vision, physical disability, deaf/hard to hearing, speech problem, mental disability, multiple disabilities. Distress financing: Taking loan or selling any belongings to pay for the healthcare. Head of household: People who were responsible for financial management and household decision making. Out of pocket expenditure: It refers to the payment made by household at the point they received health services. Typically, these include doctor's consultation fees, purchase of medicine, hospital bills laboratory fees, and copayments paid by the respondent. Insured: This includes the families who were enrolled under the national health insurance program of Nepal. Uninsured: Family who were not enrolled under the National health insurance program of Nepal. Sample selection Initially 7 wards were randomly selected from 14 wards of Baglung municipality by using lottery method. Based on the size of the insured household in each ward, sample was selected proportionately. From each selected ward based on the sample size, insured households were selected randomly by using lottery method. For every enrolled household, one comparison household (non-enrolled) was selected. Uninsured sample was selected from the nearest neighborhood of the insured household until the sample size was met.

\section{Declarations}

ETHICS APPROVAL AND CONSENT TO PARTICIPATE: Ethical Approval was taken from Institutional Review Board of Pokhara University Research Centre (IRB no 173-074-75). Participants Confidentiality was maintained and the information was used for research purposes only. Each participant participated voluntarily in this study. Written consent was taken from all the participants before the data collection.

\section{CONSENT FOR PUBLICATION: Not Applicable}

AVAILABILITY OF DATA AND MATERIAL: Due to privacy reason, data are not publicly available, the datasets used and analyzed during the current study are available from the corresponding author on reasonable request. Authors can provide study protocol, data and materials under the request. Please redirect the email to laxmanbhattbph@gmail.com for data and study protocols. 
COMPETING INTERESTS: Authors declares that they have no competing interests.

FUNDING: Authors declare that there was no any funding received for conducting this study.

AUTHORS' CONTRIBUTIONS: LDB participated in the conceptualization and design of the study, performed data collection and participated in analysis and preparation of the manuscript. SSD participated in the design and data collection of the study, performed statistical analysis and drafted the manuscript. LDB and SSD both participated in the design of the study, collected the data and drafted the manuscript. All authors read and approved the final manuscript

ACKNOWLEDGEMENTS: We gratefully thankful to the Public health program of Pokhara University including all the faculties. We thank all the study participants and all the helping hands who support and help us in every step of our study. We also acknowledge the officials of National health insurance program.

AUTHORS' INFORMATION: Laxman Bhatt and Shankar Singh Dhami both are affiliated with Faculty of Health Science, School of Health and Allied Science, Pokhara University, Kaski, Nepal.LB is student of Masters in HealthCare Management and SSD is Masters in Public Health Graduate.

\section{List Of Abbreviations}

IRC: Institutional Review Committee; HIP: National Health Insurance Program: Out of Pocket; SHSDC: Social Health Security Development Committee

\section{References}

1. WHO. Financial protection in the South-East Asia region: determinants and policy implications. Japan2017.

2. Xu K, Evans DB, Carrin G, Aguilar-Rivera AM, Musgrove P and Evans T. Protecting households from catastrophic health spending. Health affairs. 2007; 26: 972-83.

3. Dahal PK. Willingness to Pay for Health Insurance in Mangalbare Village Development Committee of Illam District. MOJ Public Health. 2017; 5.

4. WHO. Sustainable health financing, universal coverage and social health insurance. World Health Assembly Resolution. 2005; 58.

5. WHO. World Health Report: health systems financing the path to universal coverage. 2010.

6. Alhassan RK, Nketiah-Amponsah E and Arhinful DK. A Review of the National Health Insurance Scheme in Ghana: What Are the Sustainability Threats and Prospects? PloS one. 2016; 11: e0165151.

7. Saito E, Gilmour S, Rahman MM, Gautam GS, Shrestha PK and Shibuya K. Catastrophic household expenditure on health in Nepal: a cross-sectional survey. Bulletin of the World Health Organization. 2014; 92: 760-7. 
8. Gyawali B. Health Insurance System in Nepal: An Urgent Need. DEVELOPMENT ADVOCATE NEPAL. 2014.

9. GoN. National-Health-Insurance-Policy. : Government of Nepal, Ministry of Health, Social Health Security Development Committee, Kathmandu, 2013.

10. SHSDC. Annual Report. Ministry of Health, Social Health Security Development Committee Teku, Kathmandu, 2017.

11. SHSDC. Annual Report for FY 2073/74 Kathmandu: Social Health Security Development Committee, 2017.

12. Bartlett J, Deribe K, Tamiru A, et al. Depression and disability in people with podoconiosis: a comparative cross-sectional study in rural Northern Ethiopia. International health. 2016; 8: 124-31.

13. Burn $H$, Aweke $S$, Wondie $T$, et al. Podoconiosis, trachomatous trichiasis and cataract in northern Ethiopia: A comparative cross sectional study. PLoS neglected tropical diseases. 2017; 11: e0005388.

14. Philip NE, Kannan S and Sarma SP. Utilization of Comprehensive Health Insurance Scheme, Kerala: A Comparative Study of Insured and Uninsured Below-Poverty-Line Households. Asia-Pacific journal of public health. 2016; 28: 77S-85S.

15. Osei Asibey B and Agyemang S. Analysing the Influence of Health Insurance Status on Peoples' Health Seeking Behaviour in Rural Ghana. Journal of tropical medicine. 2017; 2017: 8486451.

16. Sohn $M$ and Jung M. Effects of public and private health insurance on medical service utilization in the National Health Insurance System: National panel study in the Republic of Korea. BMC health services research. 2016; 16: 503.

17. Nandi S, Schneider H and Dixit P. Hospital utilization and out of pocket expenditure in public and private sectors under the universal government health insurance scheme in Chhattisgarh State, India: Lessons for universal health coverage. PloS one. 2017; 12: e0187904.

18. Kusi A, Hansen KS, Asante FA and Enemark U. Does the National Health Insurance Scheme provide financial protection to households in Ghana? BMC health services research. 2015; 15: 331.

19. Ujunwa FA, Onwujekwe $O$ and Chinawa JM. Health services utilization and costs of the insured and uninsured under the formal sector social health insurance scheme in Enugu metropolis South East Nigeria. Nigerian journal of clinical practice. 2014; 17: 331-5.

20. Ha TH Nguyen YR, Hong Wang. The financial protection effect of Ghana National Health Insurance Scheme: evidence from a study in two rural districts. International journal for equity in health. 2011.

21. Issac A, Chatterjee S, Srivastava A and Bhattacharyya S. Out of pocket expenditure to deliver at public health facilities in India: a cross sectional analysis. Reproductive health. 2016; 13: 99.

\section{Figures}




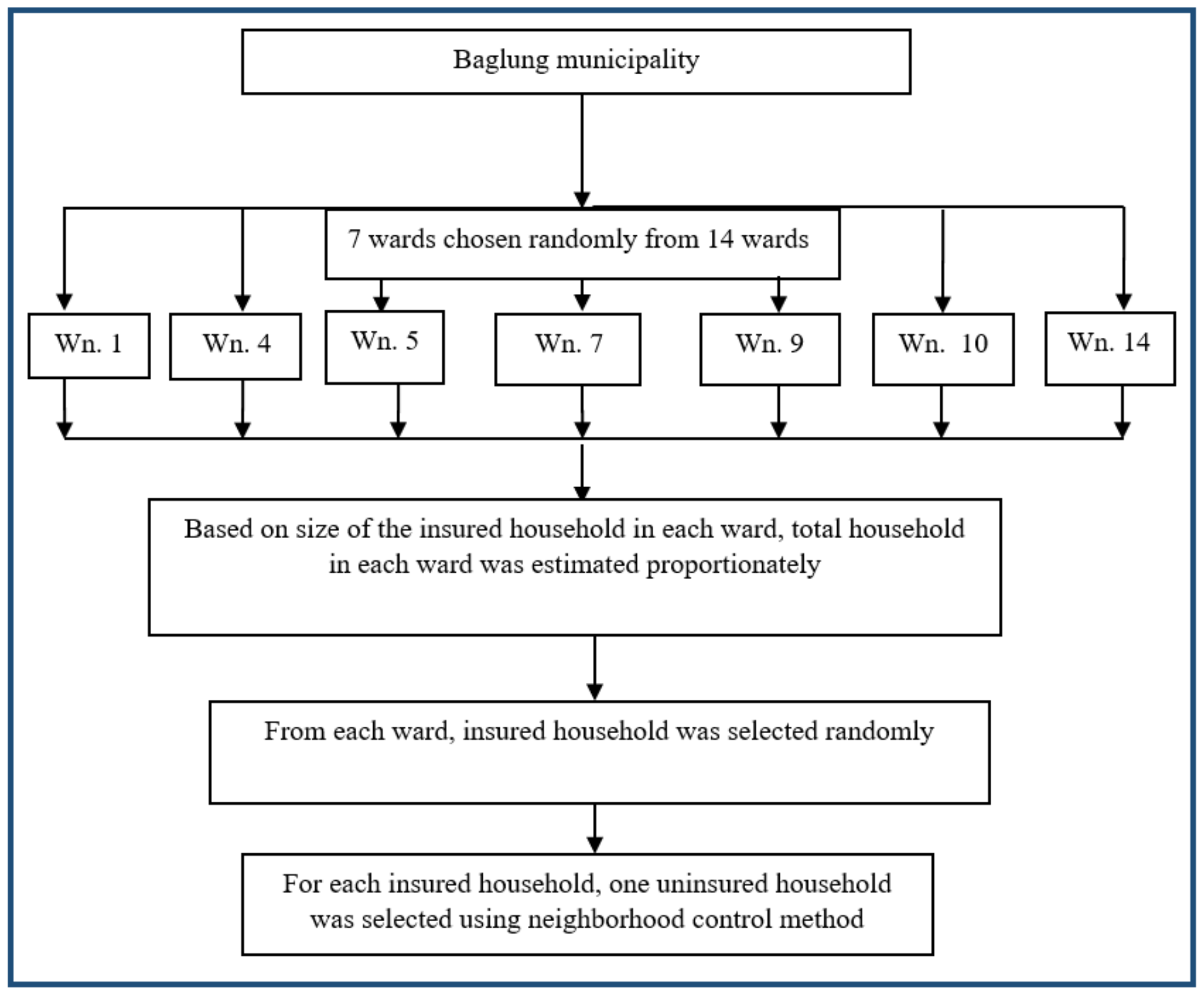

$*_{w n}=$ ward Number

Figure 1

Sampling technique 